\title{
ORIGINE DE LA LOI DU 24 SEPTEMBRE 1943
}

\author{
par M. LARTIEU \\ Inspecteur général des Eaux et Forêts.
}

La loi du 24 Septembre 1943 (1), parte au Journal Officiel du 14 Octobre 1943 , avec un rectificatil des 21 et 23 Novembre suivant, élait le complément indispensable de la loi du 12 Juillet 1941 (2).

Cette dernière avait créé, en eflet, deux catégories de pêcheurs : - d une part, ceux qui pratiquaient leur sport, soit sur les cours d eau du domaine public, soit sur les dours d eau appartenant aux propriétaires riverains, mais classés comme présentant un intérêt collectif pour la pêche, — d'autre part, ceux qui ne frécpuentaient que les cours d'eau non classés.

Tandis que ces derniers ćtaient libérés de toute obligation, les premiers étaient tenus de s affilier à une Association de pêche et pisciculture agréée par le Ministre Secrétaire d'Etat à l'Agriculture et de verser une taxe annuelle destinée à la mise en valeur du domaine piscicole national et fixée à 10 francs par le Décret d'administration publitiue du 12 Juiliet 1911 .

Par contre, la foi sur la chasse, du 28 Juin 1941 , a imposé à tous les chasseurs, outre le paiement du permis national ou départementai, l'affiliation obligatoire à une Société départementale de chasseurs avec paiement d'une cotisation de 25 francs ayant pour but l'amélioration de la chasse.

Le fait que tous les chasseurs sont placés sür un même pied d'égalité et sont soumis aux mêmes obligations, quels que soient les terrains surlesquels ils opèrent, avait provoqué des protestations contre la différence de traitement appliquée aux deux catégories de pêcheurs créées par la loi du 12 Juillet 1941. Outre la question d'égalité devant l'impôt, il avait été fait remarquer que l'exonération de la taxe en favcur d'une partie des bénéficiaires de la pêche privait les Fédérations départementales de ressources importantes.

Enfin, la discrimination introduite en matière de pêche rendait fort difficile la constatation des délits prévus par la loi du 12 Juillet 1941.

Ces considérations avaicnt amené le Comité Central des Fédérations départementales de Pêche et Pisciculture à demander, lors de la séance du

(1) Voir ci-après - p. 101 - le texte de cette loi.

(2) Voir Bulletin : ... no 125, Avril-juin 1942, p. 143. 
13 Octobre 1942, à ce que tous les pècheurs fussent tenus de s'affilier à une Issociation de Pêche et Pisciculture agréée et de verser la taxe annuelle de 10 francs.

La loi du 24 Seplembre 1943 a, rendue obligatoire la mesure préconisée par le Comité Central.

On ne peut nier que cette mesure sc justifie par le fait que tous les cours d'eau, qu'ils soient tu domaine public ou quils appartiennent aux riverains, classés ou non d'intérèt collectif pour la peche, sont surveillés au mème titre par les fonctionnaires de l'Etat. Il est donc juste que l'ensemble. des pêcheurs, qui tous bénéficient de cette surveillance, soit soumis aux mèmes obligations.

Il n est pas douteux que la loi du 24 Septembre 1943 sera très bien accueillie par la grande majorité des pêcheurs français, car elle va permettre de.consacrer chaque année à l'amélionation du domaine piscicole national des sommes plus importantes que par le passé.

Il va sans dire que cette loi ne s'applique qu'aux caux libres et ne saurait toucher les propriétaires d'étanges ou d'autres eaux closes. 